\title{
INVESTIGATION PERFORMANCE OF PICO HYDRO WATER PIPE TURBINE
}

\author{
MARWANi*, ZAhri Kadir, Ronny Egetha Putra \\ ${ }^{I}$ Department Of Mechanical Engineering. Faculty Of Engineering. Universitas Sriwijaya. Indralaya. \\ 30662. Sumatera Selatan. Indonesia \\ *Corresponding author: marwani@ unsri.ac.id
}

(Received: 2 August 2021; Accepted: 6 September 2021; Published on-line: 1 November 2021)

\begin{abstract}
The flow of water in the pipeline for household needs is a source of energy that can generate electrical energy through Pico hydro turbines or small-power water turbines. The experiment has been conducted on a 10 Watt Pico hydro turbine mounted on a water pipe against changes in water flow discharge. The turbine performance analysis is conducted experimentally (actual) and theoretically (ideal). The analysis results showed the greater the discharge flow, the greater the power generated by the turbine. In tests with a maximum discharge of $8.9 \mathrm{l} / \mathrm{min}$, the actual power of 1.121 Watts, the torque of $0.005 \mathrm{Nm}$ with a rotation speed of $2146.8 \mathrm{rpm}$ and efficiency of $12.59 \%$; while the ideal power is based on Euler turbine equation of 4.2 Watts and torque of $0.016 \mathrm{Nm}$. So, the maximum turbine power that can be generated is only $26.67 \%$ ideal. Efficiency turbine decreases with increased discharge; in this test, the maximum efficiency was $24.89 \%$ at $5.8 \mathrm{~L} / \mathrm{min}$ flow discharge.
\end{abstract}

KEY WORDS: Pico hydro turbine, Water flow rate, Hydropower, Water pipe turbine.

\section{INTRODUCTION}

Using a pico hydro turbine by utilizing the energy of water flowing in drinking water supply pipes or household clean water as an energy source that has not been utilized so far is one of the steps in energy diversification [1]. A water turbine is an energy conversion machine that converts water flow energy into mechanical work in a turbine shaft rotation. Euler turbine theory states that the torque on the shaft is equal to the change in the angular momentum of the water flow because the turbine blades deflect it and the power generated by the turbine is equal to the torque on the shaft multiplied by the rotational speed. A turbine with dimensions and size is designed for specific operating conditions/heads (discharge and pressure); if it is operated under conditions outside its design, there will be a change/decrease in performance or. in other words, less efficient use of energy [2].

The water discharge dramatically affects the performance of the water turbine [3]. If the water flow is large, the power and efficiency produced are also significant [4]. If the water flow rate is low, the power and efficiency generated will also be small [5]. The flow of water in the pipe providing drinking water or clean water for households, the discharge often changes depending on the needs. It is necessary to research or test the turbine's performance on changes in flow rate to get the optimal and efficient use of pico hydro water turbines.

A water turbine is designed to operate under certain conditions or design conditions [6]. If there is a change in operating conditions or operated outside the design conditions, there will be changes in performance. It is necessary to conduct research or testing to analyze the effect of changes in operating conditions on the performance of a turbine [7]. 
This work aims to investigate the turbine performance on changes in flow rate so that it can be seen the operating conditions where the efficiency and power produced by the turbine are maximum.

\section{METHODOLOGY}

\subsection{Experimental Setup}

Pico hydro is a hydropower production system with a maximum output capacity of $5 \mathrm{~kW}$ [8]. Smaller hydroelectric generators are the ideal devices for rural electrification [9]. They are also the most cost-effective way to generate power in this work. The schematic arrangement of the equipment used can be seen in Fig. 2.

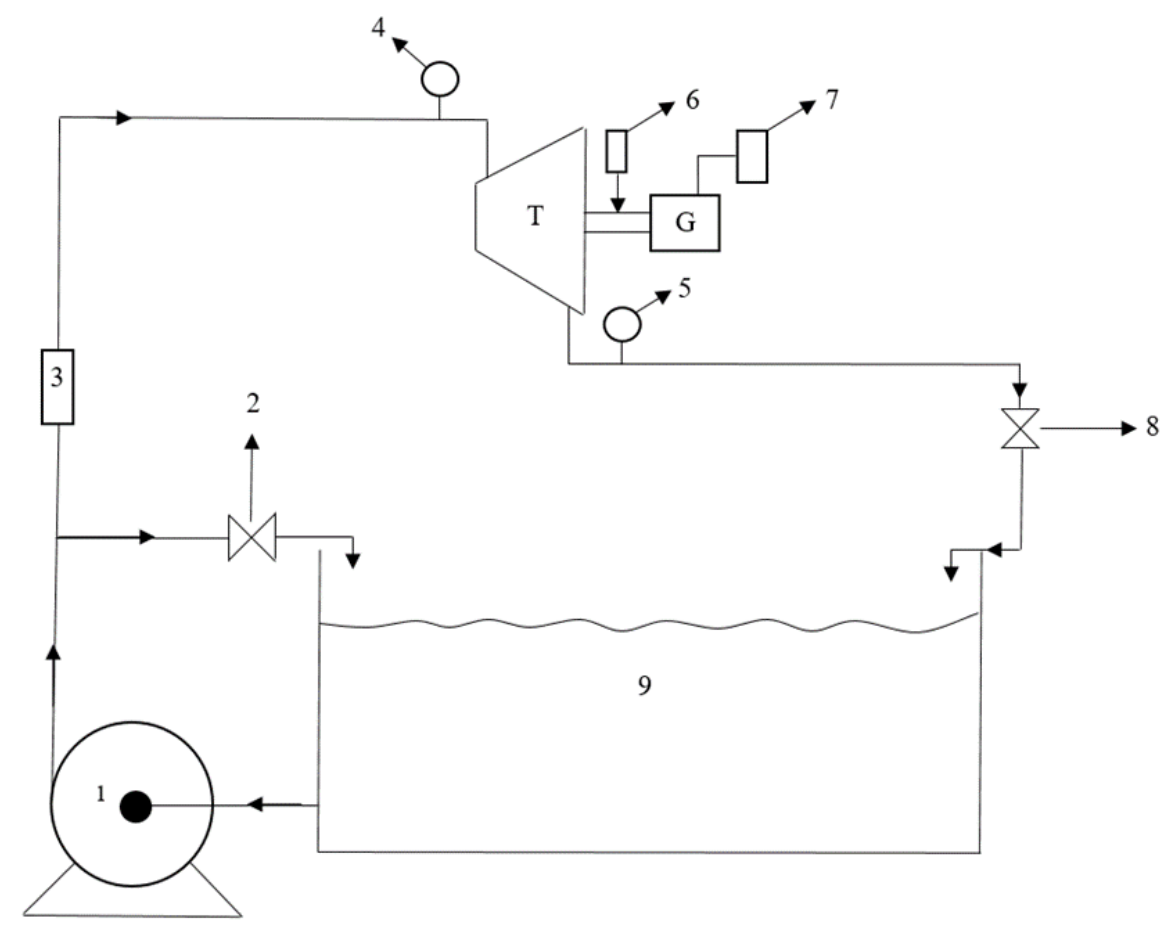

Fig. 2. Equipment Installation Schematic

1. Circulation pump

2. Bypass valve

3. Flowmeter

4. Pressure gauge 1

5. Pressure gauge 2

6. Tachometer

7. Multimeter

8. Regulatory valve

9. Water tank

Pico Hydro Turbine and blade dimensions were utilized in this work. Moreover. A $220 \mathrm{~V} / 50 \mathrm{~Hz}$ circulation pump drives energy to flow fluid (water) from the tank to the turbine.

The specifications of the Pico hydro turbine used can be seen in Table 1. 
Table 1. Turbine parameter, dimensions and size of the blade

\begin{tabular}{ll|ll}
\hline \multicolumn{2}{c|}{ Turbine parameter } & \multicolumn{2}{c}{ Dimensions and size of the blade } \\
\hline Max output voltage & $12 \mathrm{~V}$ & Angel of attack. $\alpha_{1}$ & $33^{\circ}$ \\
Max output current & $220 \mathrm{~mA}(12 \mathrm{~V})$ & Inlet Blade angel. $\beta_{1}$ & $53^{\circ}$ \\
Max pressure outlet & $1.2 \mathrm{MPa}$ & Outlet Blade angel. $\beta_{2}$ & $88^{\circ}$ \\
Water pressure & $0.05 \mathrm{MPa}$ & Outer radius runner. $r_{1}$ & $19 \mathrm{~mm}$ \\
Max power & $10 \mathrm{Watt}$ & Inner radius runner. $r_{2}$ & $16 \mathrm{~mm}$ \\
Inlet size & $20 \mathrm{~mm}$ & Nozzle Diameter. d & $4 \mathrm{~mm}$ \\
Outlet size & $20 \mathrm{~mm}$ & & \\
\hline
\end{tabular}
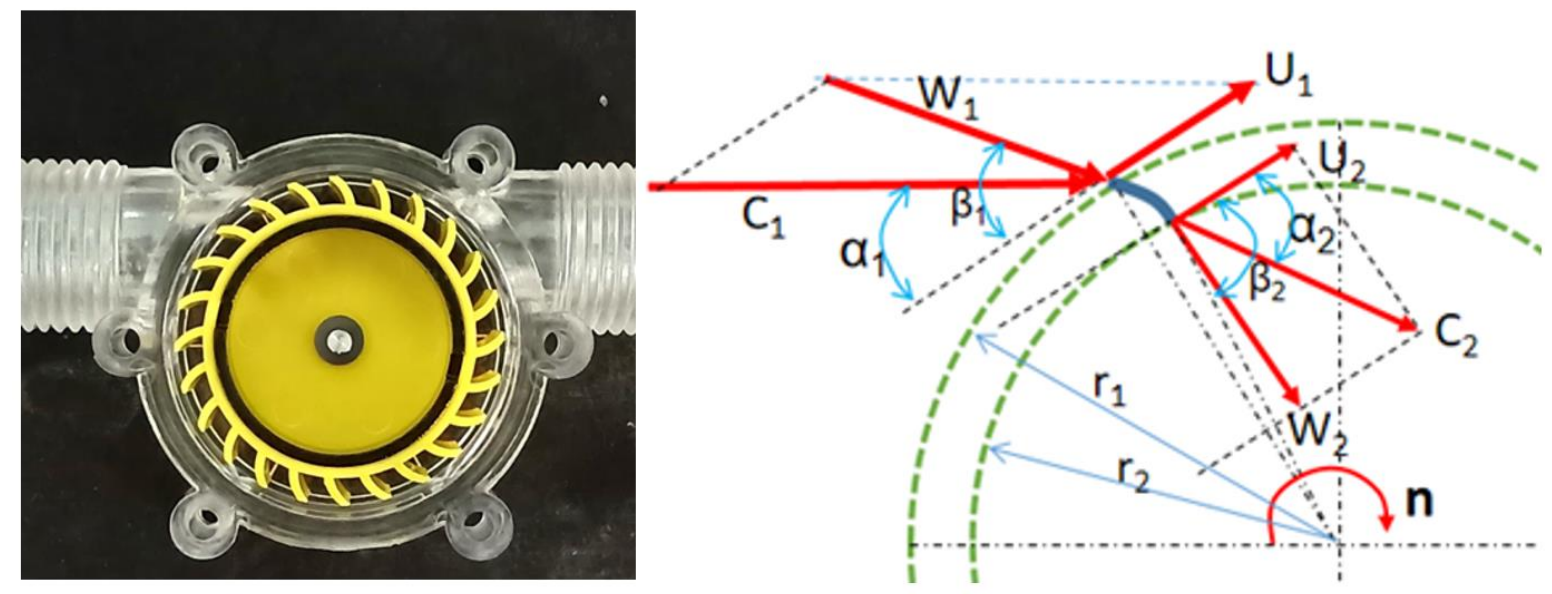

Fig. 3. Pico Hydro Turbine and Blade Dimensions

The specification performance of the turbine in Fig. 3 can be found in Table 2.

Table 2. Theoretical calculation data

\begin{tabular}{lccccc}
\hline \multirow{2}{*}{ Description } & \multicolumn{5}{c}{ Discharge $(\mathrm{l} / \mathrm{min})$} \\
\cline { 2 - 6 } & 8.9 & 8.1 & 7.4 & 6.5 & 5.8 \\
\hline $\mathrm{C}_{1}(\mathrm{~m} / \mathrm{s})$ & 11.810 & 10.748 & 9.820 & 8.625 & 7.696 \\
$\mathrm{~W}_{1}(\mathrm{~m} / \mathrm{s})$ & 8.054 & 7.330 & 6.697 & 5.882 & 5.249 \\
$\mathrm{U}_{1}(\mathrm{~m} / \mathrm{s})$ & 5.058 & 4.603 & 4.205 & 3.694 & 3.296 \\
$\mathrm{n}(\mathrm{rpm})$ & 2543 & 2315 & 2115 & 1857 & 1657 \\
$\mathrm{~W}_{2}(\mathrm{~m} / \mathrm{s})$ & 8.054 & 7.330 & 6.697 & 5.882 & 5.249 \\
$\mathrm{U}_{2}(\mathrm{~m} / \mathrm{s})$ & 4 & 4 & 4 & 3 & 3 \\
$\mathrm{C}_{2}(\mathrm{~m} / \mathrm{s})$ & 8.973 & 8.167 & 7.461 & 6.553 & 5.848 \\
$\mathrm{acos}$ & 0.442 & 0.442 & 0.442 & 0.442 & 0.442 \\
$\alpha_{2}$ & 63.8 & 63.8 & 63.8 & 63.8 & 63.8 \\
$U_{1} / C_{1}$ & 0.428 & 0.428 & 0.428 & 0.428 & 0.428 \\
$\mathrm{~T}(\mathrm{~N} . \mathrm{m})$ & 0.016 & 0.013 & 0.011 & 0.008 & 0.007 \\
$\mathrm{P}_{\text {turbine }}(\mathrm{Watt})$ & 4.220 & 3.181 & 2.425 & 1.644 & 1.168 \\
$\eta(\%)$ & 26.6 & 31.1 & 35.4 & 44.3 & 51.5 \\
\hline
\end{tabular}




\subsection{Analytical Method}

In general. the turbine converts the kinetic energy of the working fluid. In this case, water into the rotational motion of the turbine shaft. The Swiss mathematician Leonhard Euler showed in 1754 that the torque on the shaft is equal to the change in the angular momentum of the water flow as the turbine blades deflect it, and the resulting power is equal to the torque on the shaft multiplied by the rotational speed of the shaft. See Figure 1 for the following velocity chart.

To determine available power $\left(\mathrm{P}_{\mathrm{avai}}\right)$, firstly, determine pressure energy change $(\Delta \mathrm{P})$ :

$$
\Delta P=P_{1}-P_{2}
$$

Then, for $\mathrm{P}_{\text {avai }}$ becomes:

$$
P_{\text {avai }}=\Delta P \cdot Q
$$

Whereas for turbine power ( $\left.\mathrm{P}_{\text {turbine}}\right)$ :

$$
P_{\text {turbine }}=V . I
$$

Thus, for turbine performance $(\eta)$ :

$$
\eta=\frac{P_{\text {turbin }}}{P_{\text {avai }}} \cdot 100 \%
$$

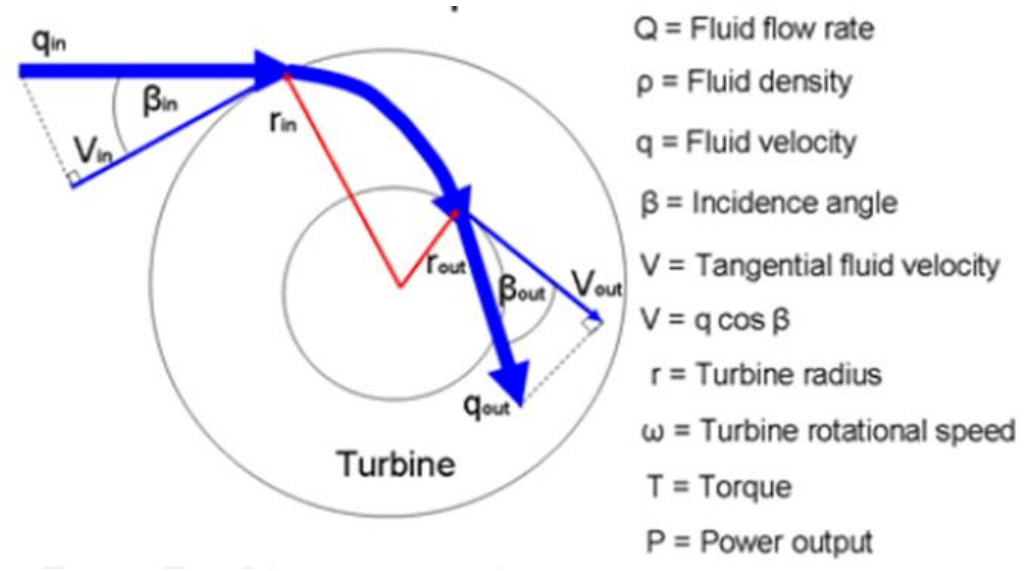

Fig. 1. Speed diagram on turbine blade

The Euler turbine theory states that the torque on the shaft is equal to the change in the angular momentum of the water flow because the turbine blades deflect it. The equation can be written as follows.

\section{RESULTS AND DISCUSSION}

The following test results are obtained from experiments that have been carried out on the installation of test equipment by varying the water discharge. The following Table 2 of data results was obtained at the time of testing. 
Table 3. Test result data

\begin{tabular}{cccccc}
\hline $\begin{array}{c}\text { Water } \\
\text { discharge } \\
(\mathbf{l} / \mathbf{m i n})\end{array}$ & $\begin{array}{c}\text { Pressure } \\
\text { (bar) }\end{array}$ & $\begin{array}{c}\text { Rotation Speed } \\
(\mathbf{r p m})\end{array}$ & $\begin{array}{c}\text { Voltage } \\
(\text { Volt })\end{array}$ & $\begin{array}{c}\text { Current } \\
\text { (Ampere) }\end{array}$ \\
$\mathbf{Q}$ & $\mathbf{P}_{\mathbf{1}}$ & $\mathbf{P}_{\mathbf{2}}$ & $\mathbf{n}$ & $\mathbf{V}$ & $\mathbf{I}$ \\
\hline 8.9 & 1 & 0.6 & 2146.8 & 12.45 & 0.09 \\
8.1 & 1 & 0.6 & 2041.7 & 12.38 & 0.08 \\
7.4 & 1 & 0.6 & 1854.6 & 12.28 & 0.07 \\
6.5 & 1 & 0.5 & 1611.5 & 12.13 & 0.06 \\
5.8 & 1 & 0.5 & 1520.1 & 12.03 & 0.05 \\
\hline
\end{tabular}

Based on the test data they obtained, then determine the turbine performance. Table 4 is calculation results based on Equation 1 to 4 using data in Table 2.

Table 4. Test data calculation results

\begin{tabular}{ccccc}
\hline $\begin{array}{c}\mathbf{Q} \\
(\mathbf{l} / \mathbf{m})\end{array}$ & $\begin{array}{c}\mathbf{P}_{\text {avai }} \\
(\mathbf{W a t t})\end{array}$ & $\begin{array}{c}\mathbf{P}_{\text {turbine }} \\
(\mathbf{W a t t})\end{array}$ & $\begin{array}{c}\mathbf{T} \\
(\mathbf{N} \cdot \mathbf{m})\end{array}$ & $\begin{array}{c}\text { Efficiency } \\
(\boldsymbol{\%})\end{array}$ \\
\hline 8.9 & 8.900 & 1.121 & 0.005 & 12.59 \\
8.1 & 7.425 & 0.990 & 0.005 & 13.34 \\
7.4 & 5.550 & 0.860 & 0.004 & 15.49 \\
6.5 & 3.250 & 0.728 & 0.004 & 22.39 \\
5.8 & 2.417 & 0.602 & 0.004 & 24.89 \\
\hline
\end{tabular}

It can be seen on Fig. 2 that the turbine rotation speed between the actual and theoretical conditions has almost the same value. In theoretical conditions (Table 1). the rotational speed is slightly larger than the actual conditions. The graph also shows that the greater the flow rate value, the rotational speed will increase both in actual and theoretical conditions.

The water velocity $(\mathrm{v})$ is directly proportional to the discharge $(\mathrm{Q})$. So, the more significant the flow rate, the greater the rotation speed. At a $\mathrm{Q}$ of $8.9 \mathrm{l} / \mathrm{min}$, the maximum rotational speed obtained below in actual conditions of $2146.8 \mathrm{rpm}$, theoretically $2543 \mathrm{rpm}$.

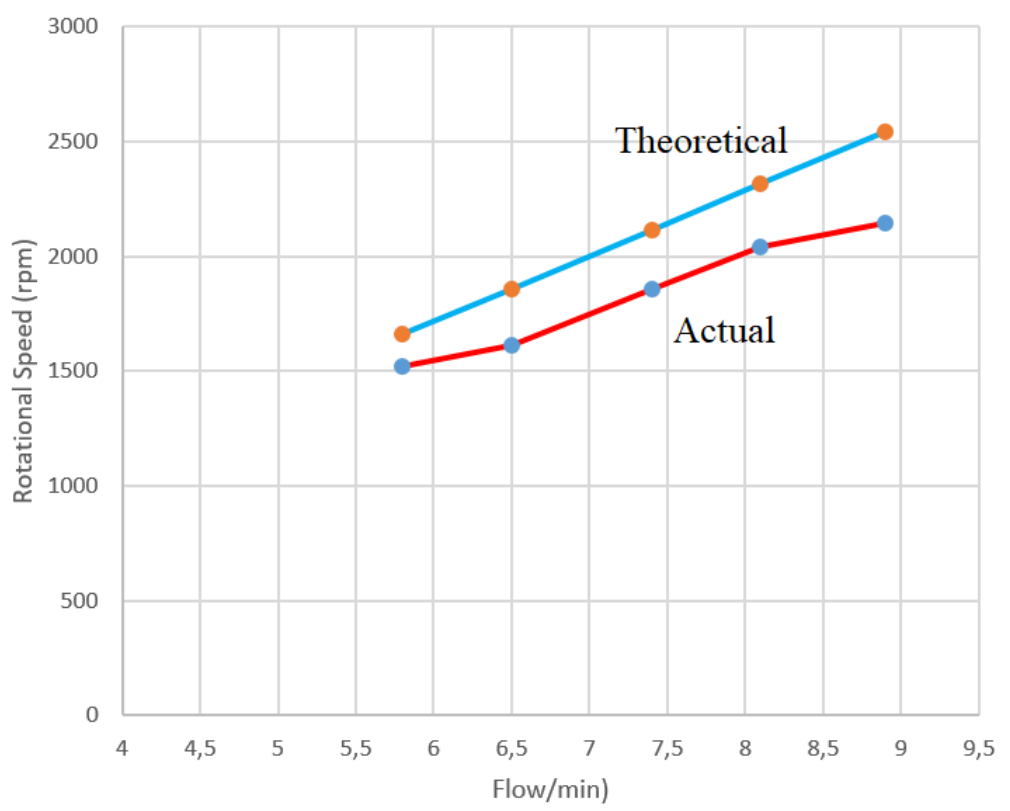

Fig. 2. Relation of rotation speed to flow rate 
Fig. 3 present available power has greater when compared to turbine power in both theoretical and actual conditions. It shows the increasing flow rate, the increase of power. The maximum available power produced at an $8.9 \mathrm{l} / \mathrm{min}$ discharge of 8.9 Watts. The maximum theoretical turbine power at a flow rate of $8.9 \mathrm{l} / \mathrm{min}$ reaches 4.22 Watt, while the maximum actual power at a flow rate of $8.9 \mathrm{l} / \mathrm{min}$ reaches 1.12 Watt. In theoretical conditions. the maximum power generated is 4.2 Watts but still unable to reach the maximum power produced by a pico hydro turbine, which is 10 Watts. The turbine power generated theoretically has a greater value when compared to the actual.

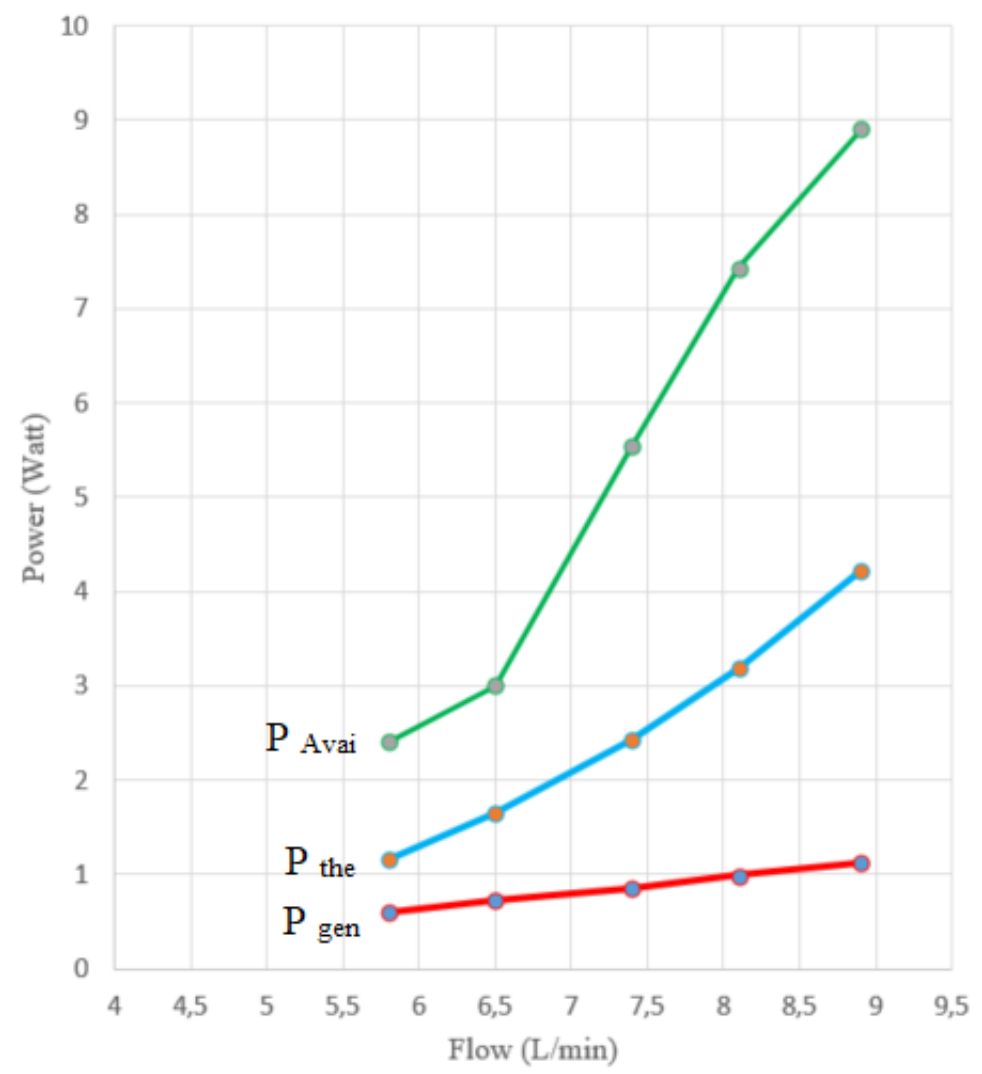

Fig. 3. Relation of power to flow rate

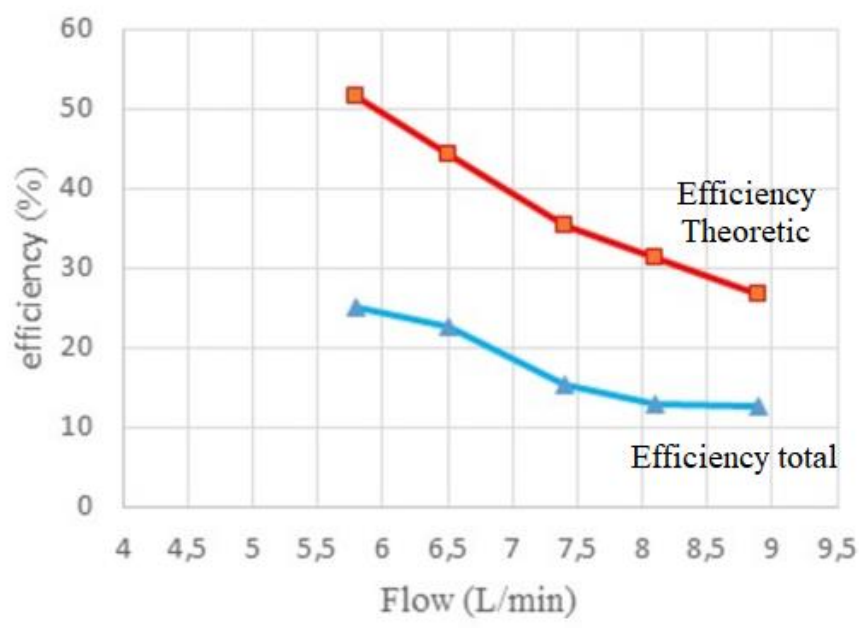

Fig. 4. Relation of efficiency to flow rate 
Fig. 4 depict the actual efficiency of the turbine decreases as the flow rate increases. The lowest flow rate produces the highest turbine efficiency. The flow rate graph against power shows that the greater the flow rate, the greater the power generated, available, and turbine power (actual). We know that the turbine efficiency is equal to the turbine power divided by the water power. Based on Equation 1 to 4, the greater the flow rate, the greater the water power lost. Based on Equation 1 to 4, the greater the flow rate, the greater the loss, resulting in decreased efficiency. Maximum efficiency is achieved by the lowest flow rate $(5.8 \mathrm{l} / \mathrm{min})$ with $24.89 \%$. Based on Fig. 4, it can also be seen that the performance analysis (ratio of actual power to theoretical power) is bigger than the actual efficiency. From this theory, the turbine's power is achieved to the maximum power generated.

\section{CONCLUSION}

Based on experimental experiments and analytical calculations, it can be concluded that the greater the flow rate, the greater the rotation speed. The greater the flow rate, the greater the power generated. The maximum theoretical turbine power at a flow rate of $8.9 \mathrm{l} / \mathrm{min}$ reaches 4.220 Watt, while the maximum actual power at a flow rate of $8.91 / \mathrm{min}$ only reaches 1.121 Watt. As the flow rate increases, the actual efficiency decreases. Maximum efficiency is achieved by the lowest flow rate $(5.8 \mathrm{l} / \mathrm{min})$ with $24.89 \%$. Maximum power is generated at a large flow rate, while maximum efficiency is generated at a small flow rate.

\section{ACKNOWLEDGEMENT}

Thanks to Universitas Sriwijaya to facilities of this research.

\section{REFERENCES}

[1] G. Go and H. T. Ahn, "Hydrodynamic Derivative Determination Based on CFD and Motion Simulation for a Tow-Fish," Applied Ocean Research, vol. 82, pp. 191-209, 2019.

[2] Ardian Syah, Manual Pembangunan PLTMH. Jakarta: Japan International Cooperation Agency, 2017.

[3] A. Židonis, D. S. Benzon, and G. A. Aggidis, "Development of Hydro Impulse Turbines and New Opportunities," Renewable and Sustainable Energy Reviews, vol. 51, pp. 1624-1635, 2015, doi: 10.1016/j.rser.2015.07.007.

[4] A. Kozyn and W. D. Lubitz, "A Power Loss Model for Archimedes Screw Generators," Renewable Energy, vol. 108, pp. 260-273, 2017.

[5] K. Sun, H. Ouyang, J. Tian, Y. Wu, and Z. Du, "Experimental and Numerical Investigations on the Eccentric Vortex of the Cross Flow Fan," International Journal of Refrigeration, vol. 50, pp. 146-155, 2015.

[6] R. I. Lewis, Turbomachinery performance analysis. Butterworth-Heinemann, 1996.

[7] C. P. Jawahar and P. A. Michael, "A Review on Turbines for Micro Hydro Power Plant," Renewable and Sustainable Energy Reviews, vol. 72, pp. 882-887, 2017, doi: https://doi.org/10.1016/j.rser.2017.01.133.

[8] D. Adanta, Budiarso, Warjito, and A. I. Siswantara, "Assessment of Turbulence Modelling for Numerical Simulations into Pico Hydro Turbine," Journal of Advanced Research in Fluid Mechanics and Thermal Sciences, vol. 46, no. 1, 2018.

[9] E. Quaranta and R. Revelli, "Performance Characteristics, Power Losses and Mechanical Power Estimation for a Breastshot Water Wheel," Energy, vol. 87, pp. 315-325, 2015, doi: http://dx.doi.org/10.1016/j.energy.2015.04.079. 